\title{
O FURTO DE ENERGIA ELÉTRICA E UMA PROPOSTA DE INTERPRETAÇÃO PENAL-CONSTITUCIONAL-AMBIENTAL
}

\author{
THE ELECTRICITY THEFT AND A PROPOSAL FOR CONSTITUTIONAL \\ INTERPRETATION OF CRIMINAL - ENVIRONMENTAL
}

\section{Luiz Gustavo Gonçalves Ribeiro}

Possui graduação em Direito pela Universidade Federal de Minas Gerais (1996), mestrado

(2005) e doutorado (2008) em Direito pela mesma Universidade. Pós-doutor pela Universitá degli Studi di Messina/IT. Atualmente é professor de Direito Penal do curso de Graduação e de Direito Penal Ambiental do curso de Mestrado em Direito Ambiental e Desenvolvimento Sustentável da Escola Superior Dom Helder Câmara.

E-mail: lgribeirobh@gmail.com

Carolina Carneiro Lima

Mestre em Direito Ambiental pela Escola Superior Dom Helder Câmara. Graduada em Direito pela PUC Minas, especialista em Direito Público com ênfase em Direito Constitucional pela Universidade Cândido Mendes. E-mail:carolcarneirolima@yahoo.com.br

Recebido em: 20/04/2017

Aprovado em: 15/08/2017

RESUMO: o artigo aborda o crime de furto de energia elétrica, popular 'gato', e sua relação com o direito fundamental à eletricidade e os impactos ambientais. O estudo apresenta o viés da cooperação e solidariedade entre os cidadãos. Trabalha aspectos escondidos nos meandros da vida social e que podem passar despercebidos ou desconectados quando se analisa aspectos criminais. Objetiva-se apontar, genericamente, que este delito dificulta o cumprimento do princípio do acesso universal a energia. Pretende-se, especificamente, descrever os impactos oriundos da impossibilidade de se precisar o gasto energético, bem como o direito e dever do indivíduo no que tange ao meio ambiente e aos direitos fundamentais. O método é o analíticodedutivo desenvolvido por meio de pesquisa teórica para responder ao problema sobre as implicações do furto de energia elétrica para o ambiente e para o acesso à eletricidade. Em conclusão, propõe-se uma interpretação das repercussões do delito de furto de energia elétrica para além dos aspectos meramente patrimoniais. O propósito deverá ser, eminentemente, constitucional-ambiental.

Palavras-chave: furto de energia elétrica; universalização do acesso à energia; produção energética; impactos ambientais; direitos difusos

ABSTRACT: the article discusses the crime of electricity theft, popular 'cat', and its relation to the fundamental right to electricity and environmental impacts. The study shows the bias of cooperation and solidarity among citizens. Works hidden aspects in the intricacies of social life and that may go unnoticed or disconnected when analyzing criminal aspects. The objective is to point out, generally, that this crime against property hinders compliance with the principle of universal access to energy. It is intended to specifically describe the impacts arising from the 
impossibility of need energy expenditure, as well as the right and duty of the individual in relation to the environment and fundamental rights. The method is the analytical-deductive through theoretical research to address the problem on the implications of theft of energy to the environment and access to electricity. $\mathrm{n}$ conclusion, it is proposed an interpretation of the repercussions of the theft of electrical energy beyond the merely patrimonial aspects. The purpose should be, eminently, constitutional-environmental.

Keywords: electricity theft; universal access to energy; energy production; environmental impacts; diffuse rights

SUMÁRIO: 1 Introdução. 2 Nuances sobre o delito de furto de energia: novas perspectivas de interpretação. 3 A universalização do acesso à energia e o meio ambiente na ótica do delito de furto. $4 \mathrm{O}$ furto de energia sob novos parâmetros interpretativos. 5 Considerações finais. Referências.

SUMMARY: 1 Introduction. 2 Peculiarities on energy larceny: new perspectives of interpretation. 3 Universal access to energy and the environment from the viewpoint of larceny. 4 Theft of energy in new interpretative parameters. 5 Final considerations.References.

\section{INTRODUÇÃO}

O Direito Penal precisa de um novo olhar. Não precisa, necessariamente, de novas leis. Carece, sim, de uma visão mais ampliada acerca da interpretação dos tipos penais existentes, vinculando-a a realidade social atual, sua repercussão em um mundo dinâmico, veloz e tecnológico. As circunstâncias em que se praticam os fatos típicos devem conter um viés integrativo com os direitos mais recentes, pois são eles que destacam os bens e valores jurídicos mais relevantes para a sociedade do momento presente.

Diante do cenário apontado, destaca-se a responsabilidade difusa, prevista constitucionalmente (art. 225, caput da CRFB), pela proteção do meio ambiente e a observância deste comando normativo em todos os aspectos jurídicos. Não há ilícitos penais ambientais somente nos fatos descritos na Lei n ${ }^{\circ}$ 9.605/98 (Lei de Crimes Ambientais), mas, sim, em toda e qualquer conduta que atinja bens jurídicos ambientais relevantes de maneira intensa ou que o sujeito passivo seja o próprio meio ambiente.

O furto de energia elétrica denominado comumente de 'gato' é um delito contra o patrimônio que se configura na subtração do bem móvel, energia, da concessionária responsável por sua distribuição. A energia é produzida e sua geração resulta em impactos ambientais que devem ser analisados, estudados e mitigados. Como calcular e compreender tais externalidades e, ao mesmo tempo cumprir a determinação de acesso universal à eletricidade, se há perda ou desvio irregular do produto gerado? Vislumbra-se, consequentemente, que o ato de subtração de energia elétrica vai mais além do prejuízo patrimonial das concessionárias de energia.

$\mathrm{O}$ estudo objetiva demonstrar o reflexo da prática de furto de energia elétrica para o acesso universal à energia, sua repercussão nos impactos ambientais e a relação de cada indivíduo no exercício de seus direitos e deveres. Pretende-se, também, cumprir a função da academia de ampliar a visão social em relação à rede encadeada de convivência, ou seja, das ações individuais e sua relação com a coletividade.

O problema que se busca responder consiste, como já explanado, nas implicações do furto de energia elétrica para o meio ambiente e para a ampliação e generalização do uso da eletricidade.

O sustentáculo teórico da pesquisa é o ecodesenvolvimento pelo qual se almeja a harmonização dos efeitos socioambientais com as respostas econômicas de cada empreendimento 
ou ação. O desenvolvimento será um resultado da gestão equilibrada dos elementos envolvidos. O foco é a busca da integração entre os valores, sociais, ecológicos e humanos na interpretação do ordenamento jurídico, direcionado neste estudo para o furto de energia elétrica.

Para tanto, utilizar-se-á do método analítico-indutivo consistente na análise particularizada do crime de furto de energia elétrica em vista de sua repercussão social-ambiental e não apenas individual-patrimonial, o que será desenvolvido por meio de pesquisa teórica, por meio da qual serão abordados aspectos doutrinários e legais.

Discorrer-se-á sobre o crime de furto previsto no art. 155 do Código Penal (Dec. Lei no 2848/1940) e sobre o furto de energia elétrica (art. 155, § $3^{\circ}$ do CP), suas implicações criminais e sociais. Uma forma de integração da norma será abordada para que se alcance uma interpretação e uma visão mais concatenada da realidade com o fato em comento. Segue-se para a universalização do acesso à energia como direito fundamental do indivíduo, sustentando que é responsabilidade de todos, em um Estado Democrático de Direito, fazer cumprir tais normas programáticas que mostram verdadeiros preceitos em um núcleo de cerne fixo que não comporta retrocessos. Ato contínuo, apresentar-se-ão os impactos da geração de energia e a dificuldade de minimizá-los quando o consumo não pode ser adequadamente calculado.

Nas derradeiras considerações, far-se-á um panorama geral do caminho percorrido, não se pretendendo alcançar uma resposta definitiva sobre a questão apresentada. Almeja-se, ao revés, iniciar um novo olhar para este tipo de crime de furto que repercute na esfera coletiva e individual, no âmbito penal, ambiental, energético, administrativo e constitucional.

Busca-se trazer ao cenário criminal parâmetros sociais novos, cujas consequências mostram-se pulverizadas em várias searas, sem olvidar que a parte especial do Código Penal é de 1940, as abordagens ambientais surgiram fortemente na década de 1970 e a Constituição da República Federativa do Brasil é de 1988, ou seja, contextos jurídicos e históricos que se entrelaçam e vão sendo alinhavados com as experiências vividas socialmente.

A proposta conclusiva é o abandono de paradigmas individualistas e patrimonialistas, pois, afinal, o furto de energia elétrica possui sérias consequências sociais e ambientais.

\section{NUANCES SOBRE O DELITO DE FURTO DE ENERGIA ELÉTRICA: NOVAS PERSPECTIVAS DE INTERPRETAÇÃO}

A tipificação do delito de furto de energia elétrica no Código Penal de 1940 foi uma inovação, pois trouxe para o bojo da norma a equiparação da energia elétrica à coisa alheia móvel, passível de apoderação por outrem invito domino, ou seja, contrariamente à vontade do detentor do direito sob o bem, no caso a concessionária de distribuição de energia. Foi um parâmetro novo, tanto que contou com esclarecimento na exposição de motivos da parte especial do Código Penal, em seu número 56, in verbis:

toda energia economicamente utilizável e suscetível de incidir no poder de disposição material e exclusiva de um indivíduo (como, por exemplo, a eletricidade, a radioatividade, a energia genética dos reprodutores etc.) poder incluída, mesmo do ponto de vista técnico entre as coisas móveis, a cuja regulamentação jurídica, portanto, deve ficar sujeita.

Assim, cessa-se, por completo, a questão acerca da controvérsia sobre ser ou não objeto passível de furto a energia elétrica ou outra que possa ser objeto de apoderamento e possua valor econômico. Trata-se de uma realidade contida na maioria das legislações contemporâneas.

Em relação ao tipo penal já inovador em seu nascedouro observa-se, mas não só nele, a necessidade de uma visão metodológica diferente daquela tradicionalmente adotada até então. É preciso que o operador do direito proceda à interpretação com base em direitos fundamentais e difusos, que se utilize de uma hermenêutica aberta, holística, na qual os efeitos, consequências e 
resultados sejam percebidos de forma plúrima e não apenas focados para a localização 'espacial' e de 'classificação' em que o delito se encontra no Código Penal - Título II, dos crimes contra o patrimônio; Capítulo I, do furto.

A análise do delito deve conter os conceitos, a principiologia e modelos do Direito Penal, sem, contudo, olvidar da integração entre as normas e do respeito reverencial aos preceitos constitucionais. Deve, entretanto, coadunar-se com o desenvolvimento social e temporal do Direito, mantendo-se alerta ao tempo presente, trazendo para a norma individual os limites requeridos pelo Direito atual.

É o que acontece com o furto de energia elétrica que foi editado para ser simplesmente um delito contra o patrimônio de um sujeito passivo determinado, pois inexiste crime sobre coisa de ninguém, abandonadas ou perdidas (res, nullius, res derelictae, res desperdita).

Todavia, a interpretação das normas, em casos concretos e abstratos, deve conciliar a consciência jurídica atual ao espírito do ordenamento jurídico. Por esta razão, o furto de energia, necessita, peremptoriamente, ser analisado juntamente com os princípios do Direito Constitucional, do Direito Ambiental, do Direito de Energia e do Direito Administrativo. A integração dar-se-á na interpretação holística do fato jurídico perpetrado ${ }^{1}$. Eis, em analogia, a hermenêutica constitucional da sociedade aberta e pluralista em que todos indistintamente vivem a Constituição como legítimo intérprete (HÄBERLE, 1997). Assim, o autor do fato ao subsumir a sua conduta a um tipo penal, aceita infringir a norma criminal e reflexamente a outros princípios do Direito.

Não estando os outros parâmetros lesionados nas elementares do tipo legal podem, por integração das normas, ser avaliados nas circunstâncias judiciais. Não se trata, repita-se, de fomentar a produção legislativa, mas, de pretender um olhar mais 'antenado' à realidade coletiva atual. Os resultados não alcançados nas elementares podem ser discutidos minuciosamente nas circunstancias judiciais em cada caso concreto.

Por necessário, é oportuno salientar não se atentará às discussões doutrinárias sobre se ocorre a subtração da energia ou o desvio, se a prática ocorre antes dou depois de aferido no medidor, se não se computa o gasto ou mede-o em menor proporção. Não é objetivo, no momento, perquirir sobre se estamos diante do delito de furto, estelionato ou furto qualificado pela fraude ${ }^{2}$. O cerne que se pretende atingir é a necessidade de um novo olhar sobre a interpretação dos ilícitos, evitando a proliferação legislativa e adequando-se as investigações, amplo senso, ao contexto social atual.

O furto de energia é o foco no momento, mas os argumentos de maneira genérica podem ser expandidos para outros tipos penais e outras contingências. Trata-se mais de um estudo sobre interpretação do direito penal, com reflexos ambientais e constitucionais pouco comuns e não usuais, mas que deveriam ser incentivados, do que sobre a exata subsunção do fato a elementares penais.

Ultrapassado o entendimento histórico da existência do delito de furto, uma melhor abordagem sobre o reconhecido "gato" faz-se imprescindível, pois o fato que o envolve passa por uma compreensão do limite entre o ilegal, o informal e o ilícito para que seja possível adentrar a seara pretendida de uma análise mais complexa do cenário envolvido (YACCOUB, 2010, p. 3).

\footnotetext{
${ }^{1}$ As decisões dos juízes devem estar em consonância com o conteúdo da consciência jurídica geral, com o espírito do ordenamento, que é mais rico do que a disposição normativa, por conter critérios jurídicos e éticos, idéias jurídicas concretas ou fáticas que não encontram expressão na norma de direito. (DINIZ, 2004, p. 94).

${ }^{2}$ A energia elétrica, é certo, tanto pode configurar o crime de furto como o de estelionato.

$[\ldots]$

Tal entendimento, porém, é contestado por Paulo José da Costa Júnior, sustentando este último que "no estelionato, a vítima, ludibriada, entrega a coisa ao agente; e, na espécie apresentada, o que se verifica é o furto qualificado pela fraude". (FRANCO; STOCCO (orgs.), 2007, p. 786).
} 
O furto de energia é muitas vezes compreendido como um 'jeitinho' "para a conta de luz chegar mais barata" e não como algo ilegal. Realidade mais grave ocorreu no início das atividades das concessionárias que não possuíam reconhecimento popular de sua atuação e existência, tornando comum a ideia de que a energia não tinha dono. A energia era reputada como algo natural, a "naturalização da energia elétrica". "O usuário não vê a energia como bem finito e um produto" (YACCOUB, 2010, p. 19).

Hoje, a consciência de que a prática do 'gato' é ilícita é amplamente difundida, principalmente em razão da crise hídrica, da democratização da informação e da própria característica e estilo de vida. A vivência atual vai de encontro à denominada "cultura do povo" que deseja ter acesso aos bens de consumo, mas não consegue arcar com o valor da energia por eles consumida, por isso a responsabilidade tem que ser ampliada, adequando-se às características sociais. O agente não pode ser analisado no contexto da sociedade de consumo atual somente em relação a sua pretensão e direito ao bem-estar, mas deve ser entendido como cidadão, sujeito de direitos e deveres. As vertentes analíticas não são segmentadas, estão totalmente conectadas.

A frugalidade da sociedade de consumo trouxe consigo problemas que se pulverizam em diversas áreas da vida, pois o indivíduo coloca no consumo (ou no consumismo) o princípio para a satisfação de seus interesses, vendo-se aprisionado por regras de vida que não são suas, mas que foram aceitas como se fossem (FORNASIER, 2012). "Por ser heterônoma a criação de tal necessidade e, ainda mais, por ser necessária a continuidade dessa ordem, para que as instituições criadoras se reproduzam, é estimulada a insaciabilidade do indivíduo" (FORNASIER, 2012, p. 198). Trata-se da imagem da liberdade, do acesso irrestrito a bens e produtos que no final das contas é uma forma de aprisionamento direto e indireto. Direto, pois altera a vida do cidadão individualmente e indireto porque atinge toda a sociedade que precisa de equilíbrio para se manter estável ambientalmente e economicamente. ${ }^{3}$

Vê-se, assim, com mais preocupação o meio ambiente, uma vez que precisamos dele para reparar ou restaurar o equilíbrio das outras esferas, sem contar que sua estabilidade depende de fatores fisiológicos e ciclos que o avanço tecnológico não consegue suprir.

O desenvolvimento industrial, o progresso tecnológico, a urbanização desenfreada, a explosão demográfica e a sociedade de consumo, entre outros fatores, têm tornado atual e dramático o problema da limitação dos recursos do nosso planeta e da degradação do ambiente natural - fonte primária de vida (PRADO, 2001, p. 16).

Diante do contexto apresentado, vislumbra-se a existência de uma miríade de características envolvidas no furto de energia, motivo pelo qual não se pode abandonar os aspectos norteadores da vida em sociedade que conduzem às responsabilidades, solidariamente colocadas, diante de todas as ações individualmente praticadas.

\footnotetext{
${ }^{3}$ Os fins e os meios do desenvolvimento exigem que a perspectiva da liberdade seja colocada no centro do palco. Nessa perspectiva, as pessoas têm de ser vistas como ativamente envolvidas - dada a oportunidade - na conformação de seu próprio destino, e não apenas como beneficiárias passivas dos frutos de engenhosos programas de desenvolvimento. O Estado e a sociedade têm papéis amplos no fortalecimento e na proteção das capacidades humanas. São papéis de sustentação, e não de entrega sob encomenda. A perspectiva de que a liberdade é central em relação aos fins e aos meios do desenvolvimento merece toda a nossa atenção. (SEN, 2010, p. 77).

[...] O desafio ambiental faz parte de um problema mais geral associado à alocação de recursos envolvendo "bens públicos", nos quais o bem é desfrutado em comum em vez de separadamente por um só consumidor. Para o fornecimento eficiente de bens públicos, precisamos não só levar em consideração a possibilidade da ação do estado e da provisão social, mas também examinar o papel que pode desempenhar o desenvolvimento de valores sociais e de um senso de responsabilidade que viessem a reduzir a necessidade da ação impositiva do Estado. Por exemplo, o desenvolvimento da ética ambiental pode fazer parte do trabalho que a regulamentação impositiva se propõe a fazer.(SEN, 2010, p. 343).
} 
À ética imperativa da solidariedade sincrônica com a geração atual somou-se a solidariedade diacrônica com as gerações futuras e, para alguns, o postulado ético de responsabilidade para com o futuro de todas as espécies vivas na Terra. Em outras palavras, o contrato social no qual se baseia a governabilidade de nossa sociedade deve ser complementado por um contrato natural. (SACHS, 2009, p. 49).

As responsabilidades são determinadas constitucionalmente e devem estar contidas em todas as searas analíticas da vida em coletividade. Com o furto de energia não pode ser diferente. É um delito de natureza permanente em que a lesão perpetua-se no tempo atingindo um bem específico (energia elétrica) que possui titular de direito, mas que contem amplo espectro, repercutindo, também, na dificuldade de se universalizar o seu acesso e na obstaculização da divisão equânime dos riscos e impactos de sua produção. Estes são liames conectividade que faltam para uma hermenêutica correta do delito em destaque na dinâmica social e jurídica hodierna - "o desenvolvimento é realmente um compromisso muito sério com as possibilidades de liberdade" (SEN, 2010, p. 378).

Para que uma política energética forte e sustentável se desenvolva, e para que ela ocorra, os cidadãos precisam se dar conta de que todos terão de se sujeitar a mudanças: altos preços da energia, abertura de determinadas áreas geográficas para a exploração energética e aceitação tanto dos benefícios quanto dos riscos da tecnologia. A energia não é um fim em si mesma, mas um meio para se atingir os objetivos de uma economia e um ambiente saudáveis (HINRICHS; KLEINBACH; REIS, 2014, p. 736).

A repercussão do delito de furto de energia, a responsabilidade social por melhor qualidade de vida e acesso a serviços essenciais, bem como a conservação do meio ambiente e a sua utilização eficiente é direito e dever em todos, em todas as esferas da vida civil, mormente diante da assunção do contrato social.

Diferente não seria para o intérprete da lei, seja ele o titular da ação penal, o detentor do poder jurisdicional ou cada cidadão em seu dia-a-dia. É imperativa uma nova abordagem para os delitos que atingem, mesmo que indiretamente, direitos ambientais, difusos e fundamentais. "Para obtermos sucesso, temos que nos envolver. É urgente adotar um posicionamento proativo. Devemos ser cidadãos informados e ativos" (HINRICHS; KLEINBACH; REIS, 2014, p. 736).

As consequências analíticas do ilícito na nova visão não requerem a edição de leis, mas clamam por um estudo das circunstâncias judiciais mais detido e profundo, com objetivo de, realmente, perceber em que contingências fáticas o delito foi perpetrado. Para tanto, é fundamental entender os reflexos percebidos nos direitos ambiental e fundamental para depois adentrar na pretensão de novo padrão analítico nos casos concretos.

\section{A UNIVERSALIZAÇÃo DO ACESSO À ENERGIA E O MEIO AMBIENTE NA ÓTICA DO DELITO DE FURTO}

O entendimento que se apresenta sobre o crime de furto de energia mostra uma perspectiva inovadora sobre o delito, trazendo para o seu contexto analítico uma gestão ecologicamente prudente dos recursos ambientais utilizados para a geração da energia. No ecodesenvolvimento, sustentáculo sob o qual se alicerça a discussão, objetiva-se uma gestão mais eficiente de todos os níveis de sustentabilidade - social, econômica, ecológica, geográfica e cultural.

O ecodesenvolvimento é reputado, doutrinariamente, quase como um sinônimo de desenvolvimento sustentável. A diferença entre ambos encontra-se no campo político, o primeiro 
adequa-se a cada caso, em busca da tecnologia e da solução para cada situação, vai de aspectos simples aos mais complexos; o segundo, visa o comprometimento global e a responsabilidade com as gerações futuras. Em razão desta particularidade é que o sustentáculo das argumentações desenvolvidas faz-se sobre o ecodesenvolvimento, uma vez que cada localidade tem ciência de suas deficiências energéticas e da necessidade de expansão do atendimento das redes.

Mais que isso, cada fato analisado pormenorizadamente e refletido nas circunstâncias judiciais merecerá uma discricionariedade própria para que se compreenda com lucidez os contornos de culpabilidade e da conduta social do agente no cenário apresentado para reflexão.

Os fatos serão analisados no contexto social em que surgiram. Cada micro ou macro coletividade tem a responsabilidade por desenhar o destino que se pretende... "a humanidade terá que enfrentar a si mesma" (LEITÃO, 2015). Os assuntos ambientais fazem parte das escolhas democráticas a serem realizadas pela República Federativa do Brasil. A segurança e o bem estar enunciados no preâmbulo da Constituição de 1988 pressupõem uma vida digna e para ela é imprescindível medidas de segurança ambiental (CASTRO, 2010) que se destaca em todas as esferas sociais.

A vida digna é objetivo, norma programática, que atinge o acesso amplo à energia que possibilitará consequentemente a redução da pobreza. A segurança do abastecimento constitui, por sua vez, a base de uma sociedade industrializada, como a atual, e garantia de uma vida com dignidade para os membros (PARENTE, 2010). "O desenvolvimento da sociedade deve se dar de forma harmônica com a natureza, de maneira a representar um progresso sustentado, equilibrado entre a aquisição e gozo das benesses patrimoniais e a manutenção da qualidade de vida" (CASTRO, 2010, p. 66).

Em suma,

para a perspectiva humana, segurança energética pode surgir vinculada às preocupações desenvolvimentistas, em que o papel do setor energético voltado para o crescimento econômico e o desenvolvimento tecnológico se vincula ao fortalecimento do ambiente no qual o indivíduo está inserido e pode adquirir cada vez mais bem-estar com o aumento e melhoria da oferta de infraestrutura pelo Estado. Nesse sentido, as atenções se direcionam tanto para os indivíduos quanto para a sociedade e o Estado. (SIQUEIRA, 2015, p. 133).

Assim, a universalização do acesso a energia ganha maior espectro, pois é levada a categoria de direito individual e humano, sendo garantida no âmbito da vida em coletividade por políticas públicas implementadas com auxílio de subsídios e metas de abrangência para as concessionárias, sob o foco de combate à "assimetria econômica", objetivando "viabilizar determinados benefícios para a inclusão social de parcela significativa da população" $\left(\right.$ SANCHES, 2011, p. 383) ${ }^{4}$. Eis aí mais um argumento acerca da censurabilidade mais potencializada sobre a prática do furto de energia.

Oportuno observar que não é só a energia elétrica que se apresenta como direito individual e humano, mas, sim, todas as formas de energia, uma vez que são fundamentais para a satisfação das necessidades dos membros da sociedade que se pauta em uma vida marcada pelo consumo.

Desde siempre la energía há sido el centro de los pasos fundamentales de la civilización. De la era prehistórica a nuestros tiempos, del descubrimiento del

\footnotetext{
${ }^{4}$ Objetivando a inclusão social por meio da acessibilidade à energia elétrica, os agentes políticos editaram diversos planos de ação governamental para melhor conduzir o gerenciamento deste objetivo. Entre eles, pode-se citar: Programa Nacional de Eletrificação Rural, denominado "Luz no Campo"; criação da Conta de Desenvolvimento Energético-CDE; Programa Nacional de Universalização do Acesso e Uso da Energia Elétrica, "Luz para Todos"; Comissão Nacional de Universalização; Programa Energia Cidadã. (SANCHES, 2011).
}

Revista de Direito Brasileira | São Paulo, SP | v. 20 | n. 8 | p. 128-145 |Mai./Ago. 2018 
fuego a la energia eléctrica, la sociedad ha evolucionado gracias a eventos históricos relacionados com la energía. Sim energia el hombre no podría existir. Por ello cabe cuestionarse cómo, hasta hoy, se há venido reconociendo el derecho a la vida, a la información, a la huega etc., despreocupándose de la cuestión energética. (PARENTE, 2010, p. 255) ${ }^{5}$.

Em função da importância que adquiriu socialmente a energia, destaca-se o compromisso advindo dos princípios da cooperação e da solidariedade. Ganha contornos mais precisos quando se verifica a inserção do meio ambiente na terceira dimensão dos direitos humanos com traços de fraternidade e, também, no momento que se vislumbra a abordagem do tema em uma Encíclica Papal, como na 'Laudato Si - Louvado sejas sobre o cuidado da casa comum'6 . Não há como não perceber a necessidade de assunção de um compromisso solidário em sua tutela, haja vista que intimamente ligado aos direitos básicos: vida, liberdade, propriedade e segurança.

O que não se pode perder é a noção de que as sociedades têm direito de melhorarem suas condições de vida constantemente, adaptando e suprindo suas condições materiais, desabrochando capacidades e potenciais nos mais variados campos da vida humana (PÁDUA, 2009), sem, contudo, cercear o acesso dos demais aos bens naturais, nem esgotá-los de maneira a comprometer definitivamente a produção energética, pois ela inexiste naturalmente no estado em que consumido, precisa de transformações tecnológicas para se tornar energia elétrica.

A energia elétrica, portanto, é um produto tecnológico advindo de transformações de fonte energéticas primárias (petróleo, gás natural, carvão, incidência solar, vento, água, urânio, tório, marés marítimas, entre outras). É também um serviço, pois precisa ser armazenada e conduzida por linhas de transmissão até seu destino final para que seja consumida e modifique a vida das pessoas.

O caminho percorrido da fonte primária até o destino final também deve ser refletido nas consequências da prática do furto de energia, uma vez que se deve atentar ao fato

de que a energia elétrica não "vem da natureza", não é resultado de um simples extrativismo. Grande parte da energia consumida no Brasil vem de usinas hidrelétricas, que têm como condição básica grandes volumes de um recurso natural: água. È imprescindível um sistema complexo como represamento, construção de hidrelétricas, cabeamentos, redes e torres e transmissão etc. para que a energia chegue até os transformadores, postes e as tomadas de nossas casas. A energia é fruto de um advento científico, de pesquisas laboratoriais e investimento tecnológico. Não é um recurso infinito, muito menos natural: é resultado de um sistema produtivo possui uma cadeia produtiva. Portanto, é um

\footnotetext{
${ }^{5}$ Desde sempre a energia tem sido o centro dos passos fundamentais da civilização. Da era pré-histórica a ao nosso tempo, do descobrimento do fogo à energia elétrica, a sociedade evoluiu graças a eventos históricos relacionados com a energia. Sem energia o homem não poderia existir. Por isto cabe questionar como, até hoje, reconheceu-se o direito à vida, à informação, à greve etc., sem se preocupar coma questão energética (tradução nossa).

${ }^{6}$ São João Paulo II debruçou-se, com interesse sempre maior, sobre este tema. Na sua primeira encíclica, advertiu que o ser humano parece "não se dar conta de outros significados do seu ambiente natural, para além daqueles que servem somente para os fins de um uso ou consumo imediatos". Mais tarde, convidou a uma conversão ecológica global. Entretanto fazia notar o pouco empenho que se põe em "salvaguardar as condições morais de uma autêntica ecologia humana". A destruição do ambiente humano é um fato muito grave, porque, por um lado, Deus confiou o mundo ao ser humano e, por outro, a própria vida humana é um dom que deve ser protegido de várias formas de degradação. Toda a pretensão de cuidar e melhorar o mundo requer mudanças profundas "nos estilos de vida, nos modelos de produção e de consumo, nas estruturas consolidadas de poder, que hoje regem as sociedades". O progresso humano autêntico possui um caráter moral e pressupõe o pleno respeito pela pessoa humana, mas deve prestar atenção também ao mundo natural e "ter em conta a natureza de cada ser e as ligações mútuas entre todos, num sistema ordenado. (FRANCISCO, 2015, p. 10/11).
}

Revista de Direito Brasileira | São Paulo, SP | v. 20 | n. 8 | p. 128-145 |Mai./Ago. 2018 
produto, um bem, um artefato, um objeto técnico-científico. (YACCOUB, 2010, p. 25/26).

Toda ação humana gera impactos, alguns são maiores e mais significativos, outros são menores, mas, não há atividade antrópica desprovida de impactos. As externalidades negativas na produção energética apresentam-se mais intensas nas fontes fósseis, entretanto, existem, igualmente, só em menor proporção, nas denominadas energias limpas ${ }^{7}$. Os impactos ambientais são descritos na Resolução do CONAMA nº 01 de 1996 como sendo qualquer alteração das propriedades físicas, químicas e biológicas do meio, oriundas de qualquer forma de matéria ou energia proveniente de ação, direta ou indireta, dos seres humanos afetando: a saúde, a segurança e o bem-estar da população; a biota; a qualidade dos recursos ambientais; as atividades sociais e econômicas e as condições estéticas e sanitárias do meio ambiente. Assim, é nítido que a geração de energia elétrica ocasiona impactos ambientais.

Essa é mais uma razão ou motivo para demonstrar que a censurabilidade do delito em destaque há que ser maior, pois enseja perdas, supressões de ordem difusa e não apenas decréscimo patrimonial.

Oportuno frisar que o objetivo na atualidade é a diversificação da matriz energética, optando-se por fontes menos impactantes, mas, como mencionado, que não se pode confundir com ausência de impactos como objetivado pela denominação - energias limpas. Limpa é a energia desprovida de impactos ou com externalidades ínfimas. O que existe de real é uma 'produção mais limpa' (CUSTÓDIO; VALLE, 2015), coadunando, ainda mais, com a responsabilização particularizada do adepto à prática do conhecido 'gato'.

Não é possível acreditar que o crescimento econômico possa dar-se de maneira ilimitada e seu uso seja livre e desprovido de consequências. Pensar assim é ignorar "a realidade biofísica do planeta, seja em termos de sua oferta limitada de recursos naturais, seja em virtude da sua capacidade limitada de absorver os impactos ambientais da ação humana" (PÁDUA, 2009, p. 18). Não se pode, portanto, coadunar, silenciando a responsabilidades visíveis e patentes, inclusive, em ações já tipificadas.

Os recursos ambientais são de toda a população e podem ser usufruídos por qualquer indivíduo "dentro dos limites constitucionais de qualquer 'aldeia global"” (MONTOLLI, 2014, p. 312). Não se pode permitir que uma pessoa apodere-se irregularmente dos bens, sem se responsabilizar, na medida e nos critérios dispostos anteriormente acerca das ações.

A ideia é estender para todas as searas analíticas a vertente do ecodesenvolvimento, na qual se procura uma tríplice vitória:

no social, porque os objetivos de desenvolvimento são sempre sociais; no ambiental, porque não temos direito de legar aos nossos filhos e netos um planeta inabitável; e no econômico, porque sem viabilidade econômica as coisas não acontecem. Esse tripé de ecodesenvolvimento é sustentado por um duplo conceito ético: de solidariedade sincrônica com todos os passageiros da nave espacial Terra e de solidariedade diacrônica coma as gerações futuras (SACHS, 2009, p. 14).

\footnotetext{
${ }^{7} \mathrm{O}$ consumo de energia pelo homem é, porém, a principal origem de grande parte dos impactos ambientais, em todos os níveis. Em uma escala micro, desencadeou, por exemplo, doenças respiratórias, com o uso primitivo de lenha. Num nível macro, é a principal fonte das emissões de gases de efeito estufa, que intensifica as mudanças climáticas e causa perda de biodiversidade. Em algumas situações, a energia não tem papel dominante, mas ainda assim é importante: é o caso, por exemplo, da degradação costeira e marinha, devida, em parte, a vazamentos de petróleo e outros desastres ambientais. (GOLDEMBERG, 2010, p. 37).
} 
O foco precípuo é a busca do bem-estar da geração presente e o não comprometimento da geração futura com uma gestão prudente do meio ambiente, cobrando-se de cada um a ética com os bens difusos e o cumprimento de suas responsabilidades.

Cada indivíduo faz suas opções e, caso opte por transitar nos meandros da ilicitude, deve arcar com a mais completa avaliação da tipicidade, ilicitude e culpabilidade alcançando a avaliação da punibilidade em idênticos parâmetros de atenção e proteção da paz social, assim como a preservação da dignidade humana.

A compreensão acerca da importância do sistema penal e o que deve ser protegido por ele diante da restrita amplitude que possui é essencial para a observância e cobrança de responsabilidades por efeitos paralelos ao objeto central de análise. Por isso, as questões apontadas não se inserem nas elementares do tipo penal e, sim, em efeitos circundantes, que se sanados, não eliminam o delito. É uma proteção mais ampliada do bem ambiental e uma cobrança de exercício de cidadania ao agente.

O direito penal é acima de tudo uma medida de proporcionalidade em todas as suas inserções.

\section{O FURTO DE ENERGIA SOB NOVOS PARÂMETROS INTERPRETATIVOS}

Em uma análise simples ou mesmo minuciosa sobre a existência de delitos acerca o furto ou desvio de energia vinculado a alguma lei ambiental ou mesmo na lei penal ambiental mais clássica, a Lei $\mathrm{n}^{\circ} 9.605$ de 12 de fevereiro de 1998, nada será encontrado. O dispositivo é apenas localizado no já comentado art. 155, § $3^{\circ}$ do CP. A criminalização existe desde 1940 e a sua interpretação permanece ao longo destes 76 (setenta e seis) anos praticamente imutável - é compreendido como um delito contra o patrimônio, desprovido de violência, sem qualquer impacto social ou coletivo adicional.

O que mudou foi a percepção das concessionárias sobre o fato e as medidas conjuntas com a Agência Nacional de Energia Elétrica - ANEEL para conter o problema que obstaculiza o exercício adequado da função de distribuir o produto da fonte geradora até as empresas e residências, garantindo-se um acesso igualitário.

Segundo a ANEEL, em 2015 "incluindo impostos, [...] o furto de energia representa um prejuízo de mais de $\mathrm{R} \$ 8$ milhões por ano ao país, ou 13,5\% do total da energia gerada" (VIEIRA, 2015). Ademais, há gastos, e grandes, das concessionárias para a perseguição dessa prática, isso para não se falar no custo do processo penal quando a prática do crime é apurada.

Frente ao contexto descrito e cônscios da íntima ligação entre o delito em comento, os impactos ambientais advindos da produção energética e a obstaculização do acesso universal a ela além dos outros gastos com a perseguição da atividade, não há outra possibilidade que não o perceber sob outros matizes.

Para uma adequada análise de um tipo penal específico, não podemos prescindir de entender a sua classificação doutrinária, ou seja, objeto material e bem juridicamente protegido, sujeitos passivo e ativo, consumado ou tentado, elemento subjetivo, modalidade comissiva ou omissiva e causas de aumento ou diminuição de pena. Nestes aspectos já é possível perceber distinções entre o furto de energia até então concebido e o furto de energia que se pretende apresentar. No primeiro modelo, o sujeito passivo era exclusivamente a pessoa jurídica (concessionária) possuidora da energia elétrica a ser distribuída e o elemento subjetivo, denominado animus furandi, vontade do agente dirigida à subtração da coisa alheia móvel para si ou para outrem, visualizado no seu especial fim de agir (GRECO, 2008) ${ }^{8}$. Nesta descrição já se

\footnotetext{
${ }^{8}$ A energia é um bem e, ao mesmo tempo, um serviço. Um bem que não vemos ou tocamos; encontra-se, portanto, no campo do intangível.Paga-se por esse "produto" que nos é oferecido. As empresas concessionárias atuam justamente fazendo a distribuição (serviço) desse bem para cada residência mediante o pagamento de uma taxa flutuante: quanto

Revista de Direito Brasileira | São Paulo, SP | v. 20 | n. 8 | p. 128-145 |Mai./Ago. 2018
} 
tem distinções. A sua intenção subjetiva sempre foi obter a energia elétrica sem o devido pagamento. Agora se pode verificar que na ausência do pagamento tem-se, ainda, a omissão quanto a divisão em solidariedade do custo da produção, da edificação das linhas de transmissão, da melhoria do sistema e da ampliação da rede que são igualmente computadas no valor da tarifas pagas pelos consumidores que não se utilizam de captação clandestina.

$\mathrm{Na}$ vertente descrita, nada é alterado no mundo acerca do cometimento do delito. Ocorreram mudanças exclusivamente na seara de verificação da existência ou não ilícito e de seu sujeito passivo. Para que o fato seja verdadeira apurado sob novas concepções é essencial que a nova análise seja percebida no mundo exterior. Assim como o delito produz impactos no mundo real, a abordagem atual sobre o tipo penal começa a exigir reflexos na devida apuração da reprimenda a ser adotada.

No momento em que se percebe que o delito possui maior abrangência e lesão social, maior será a culpabilidade stricto sensu do agente, pois maior o impacto e o sofrimento gerado por sua ação, mais gravosa será a sua conduta social, elementos integrantes das circunstâncias judiciais (art. 59 do CP) definidoras da pena a ser impingida no caso concreto.

O tipo penal,

além dos seus elementos essenciais, sem os quais a figura típica não se completa, pode ser integrado por outras circunstâncias acidentais que, embora não alterem a sua constituição ou existência, influem na dosagem final da pena. Essas circunstâncias são, como firma Aníbal Bruno, "condições acessórias, que acompanham o fato punível, mas não penetram na sua estrutura conceitual e, assim, não se confundem com os seus elementos constitutivos. Vêm de fora da figura típica, como alguma coisa que se acrescenta ao crime já configurado, para impor-lhe a marca de maior ou menor reprovabilidade". Circunstâncias, na verdade, são dados, fatos, elementos ou peculiaridades que apenas circundam o fato principal. Não integram a figura típica, podendo, contudo contribuir para aumentar ou diminuir a gravidade. (BITENCOURT, 2008, p. 588).

É compreensível que ninguém queira deixar de compartilhar e viver o "paradigma da sociedade de consumo californiana" (RIVERO, 2002, p. 200), mas não se pode distanciar as responsabilidades gerais em relação a este estilo de vida. A geração de energia é altíssima e produz impactos que a longo prazo serão cobrados da sociedade pela natureza. Mais ainda, todos indistintamente têm deveres, são corresponsáveis pelo gasto energético e devem arcar com ele. É inadmissível que um dos maiores problemas da humanidade comporte exceções de interpretação e responsabilidade. Quem pratica furto de energia elétrica não atinge apenas a empresa de distribuição deste produto, mas toda a sociedade, gerando reflexos, inclusive, para o futuro no que tange às questões ambientais. Todas as ações geram reações (Terceira Lei da Física), não seria diferente com as questões sociais.

"Não há compartimentos estanques na vida real" (LEITÃO, 2015, p. 313), as ações de cada cidadão, as opções políticas e gerenciais - tudo está interligado. O Direito, por óbvio, ciência que busca regular as relações da vida social, mantendo a paz e a harmonia da convivência, não pode furtar-se a organizar os elementos essenciais de cada conjuntura, a fim de não desconectá-lo da estrutura.

A questão energética, além de complexa pelas características ambientais e de direitos fundamentais, conectada a um mínimo existencial, ainda, tem relação com políticas de governo

mais se consome esse produto, mais caro é o serviço, mais alta é a conta a ser paga a cada mês. (YACCOUB, 2010, p. 25). 
que, no Brasil, nem sempre foram acertadas, transformando-a em algo mais tortuoso, demandando atenção de responsabilidades acentuadas no presente momento ${ }^{9}$.

A responsabilidade difrata-se por toda sociedade, encontrando-se as esferas administrativa, civil e penal localizadas em suas especificidades, com seus traços característicos particulares, mas que se interpenetram, objetivando resoluções adequadas para todas as questões, mantendo-se o equilíbrio fundamental para a vida em coletividade.

"O direito não é mero pensamento, mas força viva" [...]

o direito é um labor contínuo, não apenas dos governantes, mas de todo o povo. A vida inteira do direito, vista de relance, mostra-nos o mesmo espetáculo sem descanso e o trabalho de uma nação, que se baseia no que oferece a produção econômica e intelectual. Cada um que se encontra na situação de precisar defender seu direito participa desse trabalho nacional, levando sua contribuição para a concretização da ideia de direito sobre a terra. (IHERING, 2001, p. 27).

Observa-se ser imprescindível "transformações, tanto de caráter individual, no que diz respeito ao comportamento ecologicamente correto das pessoas, como também coletivo, no que concerne a implementação de políticas públicas eficazes no combate ao (sic) uso inadequado dos recursos naturais" (MORAES; SANTOS; BALDISSERA, 2013, p. 619). Para tanto, deve o Estado, em suas diversas funções, incrementar a conscientização e exigir comportamentos condizentes com o padrão gerencial atual que conjuga proteção ambiental com desenvolvimento tecnológico e social. "Não existe norma jurídica, senão norma jurídica interpretada, ressaltando que interpretar um ato normativo nada mais é do que colocá-lo no tempo ou integrá-lo na realidade pública (MENDES, 1997, p. 10).

Diante dos comportamentos pretendidos socialmente não se encontra a prática do 'gato' que deve ser repensado frente ao direito de acesso a energia e ao meio ambiente equilibrado.

Assim as circunstâncias judiciais devem fazer uma avaliação de ampla abordagem, principalmente porque o delito de furto de energia possui como elemento anímico a vontade deliberada e livre do agente em praticar a conduta, pois existe somente na modalidade dolosa.

A culpabilidade, em sentido estrito, avalia a censurabilidade do ato, princípio maior da individualização. Trata-se um critério de proporcionalidade a ser construído para se verificar a reprovabilidade da conduta, sendo na abordagem realizada neste estudo, muito elevada.

A conduta social, por sua vez e em idêntico sentido, aponta para o comportamento do agente perante a sociedade que, no caso concreto, mostra a desconsideração com o coletivo/difuso e a busca de uma realização unicamente individual.

As consequências do delito, também presente nas circunstâncias judiciais, por sua vez, influenciam no estudo do delito, mas se apresentam como corolário lógico ou desdobramento das duas anteriores podendo ser reputada em um bis in idem, vetado juridicamente. Esta última pode ser identificada de maneira particularizada em casos, v.g., do 'gato' gerar um incêndio, pois redundará em uma maior intensidade da lesão jurídica causada pela infração penal, porque nas outras a intensidade da lesão é grave, mas estão adstritas às características exigidas nas elementares legais do tipo.

\footnotetext{
${ }^{9}$ Deu tudo errado. Incentivou-se o consumo na véspera da escassez. A intervenção foi feita com regras que distorceram o mercado. As distribuidoras não conseguiam comprar toda a energia que forneciam aos consumidores, porque o governo forçou preços muito baixos. Elas tiveram então que comprar o que faltava no mercado livre, no qual o preço disparou. No fim, as geradoras estavam sem dinheiro pela redução do peço e as distribuidoras tiveram que pagar energia quase oito vezes mais cara do que vendiam. Quebraram. O Tesouro socorreu as empresas e ainda foram negociados empréstimos bancários tendo como aval um documento autorizando o repasse do custo ao consumidor. Ao todo, elas precisaram de R $\$ 30$ bilhões e entraram em 2015 pedindo mais recursos. A Eletrobras, no final de 2014, precisava pagar R \$ 9 bilhões à Petrobras pelo combustível fornecido pelas térmicas e não tinha como fazê-lo. Em 2015, fechadas as urnas, veio o tarifaço.Poucas vezes se viu um erro de gestão tão penoso ao consumidor (LEITÃO, 2015, p. 304/305).
} 
Tais critérios demonstram a diferença de análise sobre este furto específico e aquele preceituado no caput do art. 155 do $\mathrm{CP}$, ensejando uma elevação da pena base, por demonstrar maior censurabilidade do ato praticado. A elevação dá-se por se perceber que a conduta atinge um sujeito passivo identificado, como sempre foi entendido, mas apresenta resultados reflexos na seara ambiental, atingindo toda a geração presente, repercutindo, possivelmente, na geração futura $^{10}$. Isso para não se falar, consoante revelam Bastos, Romano e Lobão (2012), que o próprio governo federal, através do programa "Luz para Todos", considerou, o que deve ser ponderado para os deletérios fins da subtração de energia, que esta deve ser quista como vetor de desenvolvimento social, exigindo, portanto, um novo olhar sobre a conduta de subtração de energia.

A interpretação judicial que se objetiva vem de uma analogia à interpretação aberta da constituição, já mencionada neste texto. A interpretação da norma não deve ser geral, não se atendo a norma constitucional. As normas penais, mesmo de caráter subsidiário, quando necessária a sua aplicação, devem, igualmente, espelhar uma "perspectiva funcional-processual" (HÄBERLE, 1997, p. 52), levando a uma diversidade de interpretações, sem perder a segurança e o caráter de ultima ratio, porém adequando à sociedade dinâmica, plúrima, complexa e mutante da atualidade.

Propõe-se de uma gestão judiciosa do meio ambiente, visão de um desenvolvimento racional do ponto de vista ecológico. É o ecodesenvolvimento aplicado a todas as searas coletivas, adequando o vínculo de responsabilidade, ao desenvolvimento e ao direito ao bemestar. "Surge, então, a proposição de uma visão holística. Encarar o conjunto dos aspectos econômicos, políticos, culturais, sociais, ambientais... E, numa abordagem sistêmica, analisar como as várias dimensões se interpenetram e interdependem" (MONTIBILLER FILHO, 1993, p. 131).

Faz-se opção por um desenvolvimento econômico de qualidade, capaz de proporcionar qualidade de vida e bem-estar social. São as escolhas sociais, seus direitos fundamentais e os objetivos da República Federativa do Brasil unidos e direcionados para todos os setores da vida

\footnotetext{
${ }^{10}$ A repercussão social do furto de energia está estampada em julgados do Superior Tribunal de Justiça, que, refutando, em sede de Habeas Corpus, alegação de insignificância de conduta, assim entendeu:

"HABEAS CORPUS. FURTO TRIPLAMENTE QUALIFICADO TENTADO. FIOS DE ENERGIA ELÉTRICA SUBTRAÍDOS, AVALIADOS EM, APROXIMADAMENTE, R\$ 38, 00. DESVALOR SOCIAL DA CONDUTA. PATRIMÔNIO PÚBLICO. GRAVES CONSEQUÊNCIAS. REPROVABILIDADE DA CONDUTA. INUTILIZAÇÃO DO SISTEMA DE ENERGIA ELÉTRICA DEIXANDO VÁRIAS FAMÍLIAS SEM ENERGIA POR ALGUNS DIAS. INAPLICABILIDADE, NA ESPÉCIE, DO PRINCÍPIO DA INSIGNIFICÂNCIA. PARECER DO MPF PELA DENEGAÇÃO DO WRIT. ORDEM DENEGADA. 1. O princípio da insignificância, que está diretamente ligado aos postulados da fragmentariedade e intervenção mínima do Estado em matéria penal, tem sido acolhido pelo magistério doutrinário e jurisprudencial tanto desta Corte, quanto do colendo Supremo Tribunal Federal, como causa supralegal de tipicidade. Vale dizer, uma conduta que se subsuma perfeitamente ao modelo abstrato previsto na legislação penal pode vir a ser considerada atípica por força deste postulado. 2. Entretanto, é imprescindível que a aplicação do referido princípio se dê de forma prudente e criteriosa, razão pela qual é necessária a presença de certos elementos, tais como (I) a mínima ofensividade da conduta do agente; (II) a ausência total de periculosidade social da ação; (III) o ínfimo grau de reprovabilidade do comportamento e (IV) a inexpressividade da lesão jurídica ocasionada, consoante já assentado pelo colendo Pretório Excelso (HC 84.412/SP, Rel. Min. CELSO DE MELLO, DJU 19.04.04). 3. No caso em apreço, inaplicável o postulado permissivo, eis que evidenciada a relevância do comportamento perpetrado pelo paciente, principalmente porque o referido delito não se identifica como indiferente penal, visto que além da situação provocada (várias famílias ficaram sem energia por alguns dias até que a concessionária de serviço público restaurasse os fios cortados), o que demonstra a reprovabilidade da conduta, as consequências para o patrimônio público são gravíssimas e estão além do mero prejuízo monetário ou financeiro, devendo atrair para si adequada reprovabilidade. 4. Ordem denegada, em conformidade com o parecer ministerial.’'STJ - HC: 139711 SP 2009/0118984-3, Relator: Ministro NAPOLEÃO NUNES MAIA FILHO, Data de Julgamento: 9/10/2009, T5 - QUINTA TURMA, Data de Publicação: <!-- DTPB: 20091130<br> --> DJe 30/11/2009).
} 
comum. Nada mais necessário do que interligar a pratica de um ilícito a seus efeitos indiretos, já que não podem ser desvinculados de suas consequências. Ademais, os direitos fundamentais intangíveis e não podem ser reduzidos ou mitigados nunca e o direito ambiental refere-se à própria existência do ser humana com uma sadia qualidade. Então, são circunstâncias das quais o intérprete não pode abster-se de analisar.

A manutenção do diálogo e o constante repensar das questões sociais são importantes para que o direito seja, a todo tempo, reconstruído, solidificado e cumpra a sua função perante a sociedade do tempo presente.

O direito penal, mesmo subsidiário e fragmentário, quando clamado a atuar, deve render atenção à nova dimensão analítica que se destaca. Configura-se um comprometimento social e científico do mundo moderno que se relaciona de maneira mais próxima e interligada do que em outros momentos já vividos. É a realidade moldando a ciência que se apresenta com padrões sempre a posteriori para atuar aonde for necessário, sem retirar a possibilidade da condução harmônica e indicação social da solução de suas próprias demandas. O que se verificou aqui é a solução de um ponto controverso, rascunhada na Constituição da República de 1988, em razão da sociedade ambientalista que se destacava desde a década de $70 \mathrm{com}$ o preceito criminal estabelecido nos anos 1940, oriundo da evolução tecnológica e o desenvolvimento das técnicas de produção energéticas. Nada mais do que a interligação de fatores históricos e sociais na interpretação concreta de um fato típico.

\section{CONSIDERAÇÕES FINAIS}

O furto de energia elétrica, conhecido comumente como 'gato', é analisado juridicamente, seja em âmbito jurisdicional ou doutrinário, como um ilícito perpetrado exclusivamente contra a concessionária autorizada a distribuir a coisa alheia móvel por equiparação (energia elétrica). É delito permanente, pois sua execução prolonga-se no tempo, enquanto houver o desvio ou enquanto houver o consumo sem a devida aferição do medidor, haverá consumação do crime.

A interpretação e o estudo da ciência do Direito, contudo, requerem novo olhar sobre as consequências do delito; necessitamos, afinal, de nova hermenêutica e de outra maneira de se prodecer a integração das normas dentro do ordenamento jurídico. Os ramos do Direito e as leis possuem especificidades e muitas vezes são reconhecidas por nomes - 'Lei de Crimes Ambientais' ou 'Lei da Biossegurança' - entretanto, mesmo com suas particularidades não podem ser analisadas distanciadas da realidade social e da coletividade à qual se dirige diretamente.

Esse é o parâmetro abordado no presente estudo. O delito de furto de energia elétrica há que ser compreendido em suas consequências ambientais, a todos oponíveis, por se tratar de direito difuso, assim como pelo reflexo na dificuldade de se garantir a universalidade do acesso ao bem móvel, energia, descrito como direito fundamental de cada um.

Observa-se que as vertentes apresentadas apontam para uma interpretação relativa a questões jurídicas de maior relevância, se comparadas apenas a um delito contra o patrimônio. Enfatiza-se uma lesão reflexa que não pode ser olvidada ou desconsiderada contra o meio ambiente e contra direitos fundamentais individuais.

No texto, foram externadas características do delito de furto e caminhou-se para as peculiaridades do popular 'gato' em vista da correta compreensão do fato e a subsunção às elementares do tipo legal. Seguiu-se para a responsabilidade das concessionárias e dos agentes políticos em laborar para o acesso universal à energia elétrica, bem como dos empecilhos gerados pela prática irregular descrito.

Posteriormente, com argumentos de base, fez-se o amálgama da relação do consumo energético não computado e não dividido solidariamente na responsabilidade advinda dos 
impactos derivados da produção de energia e da disponibilidade do produto (bem jurídico) na rede pública.

As externalidades ambientais são dirigidas a todos, sem exceção. Mas, em razão do delito em comento, alguns tentam locupletar-se do consumo da energia sem arcar com o valor financeiro decorrente dos gastos para a geração da energia, da tecnologia para minimizar efeitos indesejados e do aparato para incrementar as redes de transmissão.

Não se pretende punições mais severas, por si sós. Pretende-se análises mais precisas sobre as questões penais que envolvem as esferas energética e ambiental.

Visa-se uma abordagem metodológica sobre as repercussões dos delitos não só em relação às vítimas diretas, como também o reflexo para as demais pessoas, para a coletividade e para o meio ambiente. Eis um alerta sobre as necessidades sociais do tempo presente e as consequências na esfera penal que atua somente em caso de lesão ou risco a bens importantes e que possam gerar efeitos graves ou intensos.

$\mathrm{O}$ estudo fomenta o debate e a abertura para outras interpretações, mais adequadas à realidade atual. Não se encerra a discussão, dá-se um start para a pluralidade de efeitos e reflexos de uma conduta, a princípio, de fácil análise, interpretação e julgamento, mas que clama por uma modificação nas bases jurídicas de sustentação, precipuamente, para integrar a avaliação ao marco de cidadania dos indivíduos e ao princípio constitucional da solidariedade ambiental.

O direito penal é fragmentário e subsidiário e sua intervenção requer, pois, que a repercussão social seja efetivamente considerada. No caso do furto de energia elétrica, propõe-se a compreensão social-ambiental e não mais a ultrapassada análise individual-patrimonialista.

\section{REFERÊNCIAS}

BALIM, Ana Paula Cabral et al. Complexidade ambiental: o repensar da relação homemnatureza e seus desafios na sociedade contemporânea. Revista Veredas do Direito. Belo Horizonte: Escola Superior Dom Helder Câmara, v.11, n. 21, 2014, p.163-186.

BASTOS, David; ROMANO, Marcus; LOBÃO, Ronaldo. A dimensão moral das perdas: o caso do furto de energia. Revista Ética e Filosofia Política. Juiz Fora: Universidade Federal de Juiz de Fora, v. 1, n. 15, maio 2012, p. 103-124.

BITENCOURT, Cezar Roberto. Tratado de direito penal: parte geral 1. 13. ed. São Paulo: Saraiva, 2008, p. 767.

BRASIL. ANEEL - Agência Nacional de Energia Elétrica. Disponível em: <http://www.aneel.gov.br> Acesso em 15 out. 2016.

BRASIL. Constituição (1988). Constituição da República Federativa do Brasil. Disponível em: <http://www.planalto.gov.br/ccivil_03/Constituicao/Constituicao.htm.>. Acesso em 30 mar. 2016.

BRASIL. Decreto-Lei n. 2848 de 07 de dezembro de 1940. Código Penal. Disponível em: <http://www.planalto.gov.br/ccivil_03/decreto-lei/Del2848compilado.htm>. Acesso em 20 jun. 2016.

BRASIL. Superior Tribunal de Justiça (STJ) (2009) HC: 139711 SP 2009/0118984-3. Disponível em:< http://stj.jusbrasil.com.br/jurisprudencia/5847432/habeas-corpus-hc-139711-sp-20090118984-3>. Acesso em: 28 set. 2016. 
CASTRO, João Marcos Adede y. Direito ambiental. São Paulo: Memória Jurídica, 2010, 144p.

CONAMA. Conselho Nacional do Meio Ambiente. 1986. Resolução Conama $n^{\circ}$ 001. Disponível em: <http://www.mma.gov.br/port/conama/res/res86/res0186.html>. Acesso em 11.05.2015.

COSTA JR., Paulo José. Código penal anotado. São Paulo: DPJ, 2005, 1392p.

CUSTÓDIO, Maraluce Maria; VALLE, Cíntia Nogueira de Lima. Energia renovável, energia alternativa e energia limpa: breve estudo sobre a diferenciação dos conceitos. In.: CUSTÓDIO, Maraluce M.(Org.). Energia e direito: Perspectiva para um diálogo de sustentabilidade. Rio de Janeiro: Lumen Juris, 2015, p. 05-39.

DINIZ, Maria Helena. Lei de introdução ao código civil brasileiro interpretada. 10. ed. São Paulo: Saraiva, 2004, 479p.

FORNASIER, Mateus de Oliveira. Consumismo e a nova ética ambiental: uma conflituosa relação. Veredas do Direito, Belo Horizonte, v.09, n. 18, p. 189-208, julho-dezembro 2012.

FRANCISCO. Laudato Si. Carta Encíclica sobre o cuidado da casa comum. (24.05.2015). São Paulo: Paulus/Loyola, 1998. 144p.

FRANCO, Alberto Silva; STOCO, Rui (coords.). Código penal e sua interpretação: doutrina e jurisprudência. 8. ed. São Paulo: Revista dos Tribunais, 2007, 1822p.

GOLDEMBERG, José. Energia e desenvolvimento sustentável. 2. reimpr. São Paulo: Blucher, 2014, 94p. (Série sustentabilidade; v. 4/José Goldemberg, coordenador).

GRECO, Rogério. Código penal comentado. Niterói: Impetus, 2008, 1531p.

HÄBERLE, Peter. Hermenêutica constitucional: a sociedade aberta dos intérpretes da constituição - contribuição para a interpretação pluralista e procedimental da constituição. Tradução Gilmar Ferreira Mendes. Porto Alegre: Sergio Antonio Fabris, 1997, 55p.

HINRICHA, A. Roger; KLEINBCH, Merlin; REIS, Lineu Belico dos. Energia e meio ambiente. Tradução Lineu Belico dos Reis, Flávio Naron Vichi, Leonardo Freire de Mello. 5. ed. São Paulo: Cengage Learning, 2014, 764p.

IHERING, Rudolf Von. A luta pelo direito. Tradução J. Cretella Jr. e Agnes Cretella. 2. ed. São Paulo: Revista dos Tribunais, 2001, 101p. (coleção RT Textos Fundamentais).

LEITÃO, Míriam. História do futuro: o horizonte do Brasil no século XXI. Rio de Janeiro: Intrínseca, 2015, 480p.

MENDES, Gilmar Ferreira. Prefácio. In.: HÄBERLE, Peter. Hermenêutica constitucional: a sociedade aberta dos intérpretes da constituição - contribuição para a interpretação pluralista e procedimental da constituição. Tradução Gilmar Ferreira Mendes. Porto Alegre: Sergio Antonio Fabris, 1997, p. 9-10.

MONTIBELLER FILHO, Gilberto. Ecodesenvolvimento e Desenvolvimento Sustentável: conceitos e princípios. Textos de economia, Florianópolis, v.04, n. 01, p. 131-142, 1993. 
MONTOLLI, Carolina. A legitimidade jurídica do meio ambiente face à responsabilização penal e aos direitos da comunidade ambiental. In.: REZENDE, Elcio Nacur; BIZAWU, Kiwonghi (orgs.). Direito ambiental e desenvolvimento sustentável: uma redefinição da consciência ambiental planetária. Belo Horizonte: Escola Superior Dom Helder Câmara - EDSHC, 2014, p.299-315.

MORAES, Daniel Corrente; SANTOS, Marcelo Loeblein dos; BALDISSERA, Luciano Bonato. A implementação da geração de energia elétrica de forma distribuída como vetor na busca pelo desenvolvimento sustentável. $2^{\circ}$ Congresso Internacional de Direito e Contemporaneidade, Santa Maria-RS, edição 2013, p. 613-635.

PÁDUA, José Augusto. Introdução. In.: PÁDUA, José Augusto (org.). Desenvolvimento, justiça e meio ambiente. Belo Horizonte/São Paulo: UFMG/Peirópolis, 2009, p. 17-20.

PARENTE, Alessio. Principios de derecho europeo de la energía. Pamplona: Aranzadi/Thomson Reuters/Universidad de Castilla-La Mancha-UCLM/Cortes de Castilla-La Mancha, 2010. 322p.

PRADO, Luiz Regis. Crimes contra o ambiente: anotações à Lei 9.605, de 12 de fevereiro de 1998. 2. ed. rev. atual. e ampl.. São Paulo: Revista dos Tribunais, 2001. 352p.

RIVERO, Oswaldo de. O mito do desenvolvimento: os países inviáveis no século XXI. Tradução Ricardo Anibal Rosenbusch. Petrópolis: Vozes, 2002. 222p. (coleção Questões Mundiais).

SACHS, Ignacy. Caminhos para o desenvolvimento sustentável. Rio de Janeiro: Garamond, 2009. 96p. (coleção Ideias Sustentáveis).

SACHS, Ignacy. Prefácio: Ecodesenvolvimento e justiça social no Brasil. In.: PÁDUA, José Augusto (org.). Desenvolvimento, justiça e meio ambiente. Belo Horizonte/São Paulo: UFMG/Peirópolis, 2009, p. 13-15.

SANCHES, Luiz Antonio Ugeda. Curso de direito da energia: história, Tomo I. São Paulo: Instituto Geodireito, 2011.

SEN, Amartya. Desenvolvimento como liberdade. Tradução Laura Teixeira Motta. São Paulo: Companhia das Letras, 2010. 461p.

SIQUEIRA, Danielle Cynthia. Segurança energética e segurança humana em perspectiva. In.: SOUZA, Matilde de; TEIXEIRA, Rodrigo Correa; ZAHREDDINE, Danny (orgs.). Meio ambiente: debate político central do século XXI. Belo Horizonte: PUC Minas, 2015, p. 121-135.

VIEIRA, Gadner. Como solucionar o problema do roubo de energia Brasil. Ambiente Energia: meio ambiente, sustentabilidade e inovação. Publicado em 26 de maio de 2015. Disponível em: $<$ http://www.ambienteenergia.com.br/index.php/2015/05/como-solucionar-o-problema-roubo-deenergia-brasil/26289>. Acesso em: 19 jun. 2016.

YACCOUB, Hilaine. "Gato" de energia elétrica: do público ao privado, do "jeitinho" ao crime. V ENEC - Encontro Nacional de Estudos do Consumo e Tendências e ideologias do consumo no mundo contemporâneo. 15, 16 e 17 de setembro de 2010 - Rio de Janeiro-RJ. Disponível em: 
<http://www.estudosdoconsumo.com.br/artigosdoenec/8.1.6-YaccoubGato_de_energia_eletrica.pdf $>$. Acesso em: 18 jun. 2016.

YACCOUB, Hilaine de Melo. Atirei o pau no 'gato': uma análise sobre o consumo e furto de energia elétrica (dos "novos consumidores") em um bairro popular de São Gonçalo-RJ. 2010. 274f. Dissertação (Mestrado em Antropologia - Antropologia Social) - Universidade Federal Fluminense, Departamento de Antropologia do Instituto de Ciências Humanas e Filosofia, Niterói, 2010. 